\title{
Lauzerte
}

Dolmen de Terrier Blanc

\section{Bernard Pajot}

\section{(2) OpenEdition \\ 12 Journals}

Édition électronique

URL : http://journals.openedition.org/adlfi/10888

ISSN : 2114-0502

Éditeur

Ministère de la culture

Référence électronique

Bernard Pajot, "Lauzerte », ADLFI. Archéologie de la France - Informations [En ligne], Midi-Pyrénées, mis en ligne le 01 mars 1997, consulté le 20 avril 2019. URL : http://journals.openedition.org/adlfi/10888

Ce document a été généré automatiquement le 20 avril 2019.

(c) Ministère de la Culture et de la Communication, CNRS 


\section{Lauzerte}

\section{Dolmen de Terrier Blanc}

\section{Bernard Pajot}

Date de l'opération : 1988 (SD)

Inventeur(s) : Pajot Bernard

1 En 1988, B. Pajot a effectué un sondage sur une structure du Bas Quercy qui paraissait bien devoir appartenir à un petit monument mégalithique. Le site était connu dans la littérature sous l'appellation « menhir de Peyresourde », interprétation erronée comme a $\mathrm{pu}$ le démontrer cette intervention. Le sondage, destiné à vérifier la nature du monument, a été pratiqué à l'emplacement supposé de la chambre funéraire: il s'est révélé négatif puisque le substratum composé par le calcaire lacustre du Quercy blanc a été atteint sans qu'aucun vestige n'ait pu être retrouvé excepté quelques esquilles osseuses en position remaniée.

2 Il ne subsiste plus donc de ce dolmen qu'un montant long de $2 \mathrm{~m}$ et une grande dalle d'environ $4 \mathrm{~m}^{2}$ correspondant à la table supposée de ce monument mégalithique très dégradé.

\section{INDEX}

Index chronologique : Chalcolithique

Index géographique : Midi-Pyrénées, Tarn-et-Garonne (82), Lauzerte

operation Sondage (SD) 